\title{
Aspectos ético-metodológicos do fazer etnográfico a partir do convívio com usuários de crack
}

\author{
YGOR DIEGO DELGADO ALVES \\ Universidade Federal de São Paulol, São Paulo, São Paulo, Brasil \\ PEDRO PAULO GOMES PEREIRA \\ Universidade Federal de São Paulol, São Paulo, São Paulo, Brasil
}

DOI 10.11606/issn.2316-9133.v27i1p376-398

resumo: A etnografia em ambientes onde ocorrem práticas ilícitas, certamente nos impõem questões ético-metodológicas da maior relevância. Conviver com as pessoas, nestes casos, envolve riscos específicos, tanto aos pesquisadores quanto a seus interlocutores. Incorrer em atos ilegais pode se revelar uma contingência para se permanecer no campo, onde as barreiras legais se somam aos limites fixados pelos corpos. O uso da droga é capaz de sugestionar uma ética própria que não é inerente a ela, mas condicionada por uma situação que foge radicalmente ao controle do antropólogo. Os usuários de crack se revelaram detentores de conhecimento acurado sobre sua condição de vida e bons parceiros na produção de conhecimento acadêmico a respeito deles mesmos.

palavras-chave: etnografia; ética; metodologia; crack; observação participante

Ethic-methodological aspects of ethnographical work from living together with crack users

abstract The ethnography in environments where there are illicit practices certainly imposes ethical and methodological issues of greater importance. Living with people, in these cases, involves specific risks, both to the researchers and to their interlocutors. Incurring in illegal acts may prove to be a contingency to remain in the field, where legal barriers add up to the limits set by bodies. The use of the drug can suggest an ethic of its own that is not inherent to it but conditioned by a situation that is radically beyond the control of the anthropologist. Crack users have revealed accurate knowledge of their living conditions and good partners in the production of academic knowledge about themselves.

keywords ethnography; ethics; methodology; crack cocaine; participant observation 


\section{Introdução}

No presente artigo serão discutidos os dilemas éticos e as dificuldades operacionais da etnografia, com base na experiência adquirida a partir da pesquisa de campo realizada entre usuários de crack na região central de cidade de São Paulo, entre os anos de 2012 2014. Esta experiência será cotejada com excertos da literatura sobre metodologia e ética da pesquisa que orientaram tanto o trabalho de campo, quanto a escrita da tese de doutorado em antropologia social do primeiro autor.

As barreiras e desafios a serem vencidos se iniciaram com as primeiras tentativas de aproximação com o campo. Puderam ser rapidamente superadas pelo auxílio de um guia usuário de crack pertencente ao círculo social do etnógrafo. As possibilidades então abertas à interação nas rodas de crack e aspectos cruciais da cultura de uso, acabaram por nos levar a uma postura mais próxima do participante observador.

Consideramos importante ressaltar dentro do que chamamos de cultura do uso do crack "a profunda heterogeneidade dos modos de consumo (da droga), das razões, crenças, valores, ritos, estilos de vida e visões de mundo que o sustentam." (MACRAE, 2004, p.40). Com isto buscamos uma perspectiva que fuja das classificações estritamente farmacológicas das substâncias psicoativas que, no geral, quase nenhum peso atribuem a fatores de ordem social ou cultural. Desde Howard Becker (2008) sabemos o quanto as ideias dos consumidores sobre certa substância psicoativa influenciam seus efeitos e o modo como são usadas. Como nos aponta Gilberto Velho, pioneiro dos estudos antropológicos sobre drogas no Brasil, "não é a droga em si, mas são os usos da droga que importam; o que tem significado sociológico, antropológico, é o uso da droga" (LABATE et. al., 2008, p.125).

O efeito empatogênico da experiência de fumar crack teve consequências sobre a pesquisa, principalmente na dinâmica dos diálogos com os interlocutores, que apenas foram possíveis, da forma como se deram, pela confiança conquistada em campo. Nestes locais, as condições eram as impostas pelo meio, o que exigiu uma grande dose de sinceridade e abertura quanto aos objetivos da pesquisa. Longe de acrescentar mais dificuldades, esta postura possibilitou compartilhar parte significativa dos textos escritos com os usuários de crack e obter importantes contribuições.

Algumas dificuldades técnicas como a impossibilidade do manejo de caderno de campo nas cenas de uso e os procedimentos que vieram a tornar viáveis as gravações são 
consideradas em consonância com os riscos ao antropólogo e interlocutores. Por fim, considerações éticas quanto a divulgação, obtenção dos dados e conclusões do trabalho surgem ao se levar em conta o contexto proibicionista em que se dá o debate sobre drogas no Brasil.

O proibicionismo impôs uma ordem valorativa sobre diferentes substâncias psicoativas, o que trouxe consequências à produção acadêmica que "terminou entrincheirada, na maior parte das vezes do lado "certo" da batalha, ou seja, na luta contra as drogas." (FIORE, 2012, P.9). Um dos fatores que levaram à proibição de certas substâncias foi o processo de urbanização caótica e o temor das elites com seu descontrole. O que ensejou políticas repressivas sobre produtores, consumidores e vendedores de drogas. Nossa pesquisa se realizou no interior deste tensionamento.

\section{As dificuldades iniciais em acessar o campo e a importância de um guia}

A prática etnográfica baseia-se na pesquisa de campo com observação participante desde os primórdios da antropologia cultural (BERNARD, 2008). Envolve aproximação e serve-se da observação e anotação de informações acerca da vida de pessoas capazes de se sentirem suficientemente confortáveis com a presença e proximidade do pesquisador. Além disso, permite certo tipo de conhecimento experimentado que possibilita uma fala convincente sobre o tema pesquisado a partir das entranhas do etnógrafo ${ }^{1}$.

Cabe ressaltar que nem todo trabalho de campo é observação participante, mas toda observação participante é trabalho de campo, pois coloca o antropólogo onde a ação acontece. Permite participar de rituais e conversar sobre temas sensíveis, aprender o linguajar e experimentar um estilo de vida tanto quanto for possível. É importante a capacidade de agir de modo a permitir o "fluir" do cotidiano ao seu redor, adquirir conhecimento necessário para saber, por exemplo, quando rir e onde está a graça, assim como para fazer rir propositalmente.

A observação participante consiste em imergir em uma cultura e aprender como sair desta imersão para intelectualizar a partir do que foi visto, escutado e experimentado; e depois, colocar tudo em perspectiva e escrever convincentemente. Trata-se de estar pessoalmente interessado nas ocorrências do local, inclusive fofocas, de apresentar-se cada

\footnotetext{
${ }^{1}$ Fala esta que pode versar desde o consumo de ecstasy em meio a dança nas raves cariocas (ALMEIDA; EUGENIO, 2008), até o uso do crack por todo um dia no centro de São Paulo.
} 
vez mais de acordo com o jeito local para acessar os detalhes da vida familiar, da preparação ou obtenção e consumo dos alimentos e da toalete. Ater-se às habilidades de manufatura, como confeccionar o cachimbo de tragar o crack, analisar as querelas, as cenas de uso, fatos frequentemente triviais, embora, muitas vezes dramáticos e sempre significativos.

Aparentemente, pelos relatos de experiências etnográficas, quanto mais vezes se é visto, menos preocupação se causa, até se tornar despercebido. Porém, sempre se faz necessária uma primeira abordagem, um momento de chegada. Em um ambiente de atividade proibida e perseguida, como o do uso crack, devido ao constante risco de investidas punitivas por parte da polícia, a recepção aos desconhecidos e a vigilância são atividades exercidas, ao menos na região central da cidade de São Paulo, a partir de certos papéis, como o de "contenção" ${ }^{2}$ de determinada "biqueira" ${ }^{3} \mathrm{Na}$ "biqueira", com possibilidade de permanência para socialização e consumo do crack, mesmo o desconhecido apresentado na companhia de antigo frequentador será alvo da inquirição a respeito de suas credencias para lá estar. De quem é conhecido? Qual o seu propósito? O antropólogo descobrirá que o cardápio de motivos para se estar ali não é muito variado: ou irá adquirir droga e rapidamente se retirar, ou irá consumi-la no fumódromo. Caso não tenha papel aceitável será imediatamente convidado a "fazer o peão", ou seja, retirar-se do local e só retornar caso possa se encaixar.

As primeiras incursões ao campo foram realizadas na região do centro de São Paulo conhecida como Cracolândia, nas tentativas iniciais nem sequer foi possível chegar ao local, demorando-se o pesquisador no reconhecimento dos arredores. Nas primeiras oportunidades de adentrar na cena de uso, observávamos, geralmente, a certa distância sem conseguir deter-nos entre os usuários de crack. Foi encontrado um lugar de observação em um bar situado em frente a uma mureta utilizada para recostar-se durante o consumo da droga. Lá, podiam-se beber garrafas de água e sentar-nos ao balcão ou em uma das três mesas disponíveis, obter informações com os frequentadores e conversar com os usuários - presenças habituais no estabelecimento para comprar cigarros, isqueiro, salgados - além de presenciar a dificuldade destes para usar o banheiro. Foi possível testemunhar o drama de uma jovem expulsa do bar; ao procurar saber do balconista as razões para esse tipo de tratamento, soube-se que se ela não consome, não há como

\footnotetext{
${ }^{2}$ Uma espécie de vigia do local.

${ }^{3}$ Como são chamados os locais de venda, por vezes também de uso de drogas em São Paulo.
} 
justificar seu uso do banheiro e o respectivo gasto com água. Pôde-se presenciar um pouco das dificuldades enfrentadas por mulheres usuárias para manterem a higiene na rua. Fora do bar, na calçada em frente, ou na rua, entre os usuários de crack, a situação não é tão diferente, caso não se esteja lá para fumar crack, não há como permanecer sem causar algum incômodo. Assim sendo, aos poucos, foi-se compondo um visual adequado à permanência e circulação na cena. Para Edward MacRae (2004), em uma situação de campo deve-se, na medida do crível, livrar-se dos signos mais obstrutivos do trabalho. As vestimentas associadas à classe média colocam o antropólogo em situação pouco confortável e digna de suspeição no campo ${ }^{4}$. A nova indumentária foi composta por boné, propositalmente com inscrições do cantor Bob Marley, isqueiro adquirido quando da primeira tentativa de incursão, maço de cigarros e óculos escuros, estes últimos ajudariam, como pensado na época, a esconder o olhar curioso e de não usuário ${ }^{5}$. O fato de não sermos usuário era também denunciado pelo sobrepeso, visível principalmente na face, como revelado depois. ${ }^{6}$

O modo inicial de acessar o campo foi alterado quando fomos indicados a Newman, um engenheiro da nossa faixa etária, por volta de 45 anos de idade na época, e usuário constante de crack. O contato foi feito por meio de dois colegas do ensino médio, ambos haviam sido, assim como nós, usuários de drogas durante a juventude; o encontro com Newman foi marcado por telefone ${ }^{7}$. Ele acabou sendo um guia (WHYTE, 2005 [1943], p. 351) de nossa entrada no campo, o que foi um grande facilitador do acesso. O fato dele ser do mesmo círculo social do pesquisador não parece ter tido maior importância na qualidade da relação que desenvolvemos. Boas relações também foram estabelecidas com outros interlocutores provenientes de estratos sociais diversos do nosso. O que parece ter sido mais importante foi o uso pregresso de drogas, isto nos dotava de certo repertório de expressões próprias ao contexto que desejávamos acessar ${ }^{8}$. Mais ainda no caso de Newman, compartilhávamos termos de uma época, anos 80 e 90, vivida por ambos. Esta experiência pregressa permitiu também tecer questões de ordem prática a respeito da

\footnotetext{
${ }^{4}$ Em suma: faz parecer polícia, segundo os esclarecimentos dos usuários em mais de uma ocasião.

${ }^{5}$ Ao se fumar crack, se adquire um olhar específico que denuncia o consumo da droga. A sua ausência, por outro lado, acusa o não uso.

${ }^{6}$ Também havia pouco tempo para a dedicação ao campo no início da pesquisa, visto que era entre o período do pesquisador deixar a filha na escola e retornar para buscá-la quatro horas e meia depois.

${ }^{7}$ A primeira conversa foi através da rede social Facebook.

${ }^{8}$ No entanto, devemos tomar certo cuidado. Por tratar-se de ambiente relativamente próximo ao do pesquisador; por este possuir histórico de uso intensivo de drogas, o que poderia contribuir para obtenção da confiança necessária ao trabalho etnográfico baseado na qualidade das relações. Há sempre de se tomar precações para que a natureza da confiança e envolvimento pessoal nas relações de campo em excesso não enviese a pesquisa. (JOHNSON, 1983)
} 
dinâmica do uso da droga que somada às questões advindas da leitura de estudos sobre o uso de substâncias como Zinberg (1984), Grund (1993), Fernandez (2007), Malheiros (2012; 2013) e Edward MacRae (2004; 2013) terminou por fornecer o esquema conceitual, disciplinadamente apreendido, possibilitador de certo olhar (OLIVEIRA, 1998) sobre os ambientes de uso, as representações e práticas que neles se desenrolavam.

Era impossível ir a campo e fazer as anotações in loco, devido ao fato de levantarse suspeitas imediatas na Cracolândia, mesmo posicionando-se relativamente distante dos usuários, dentro de um bar ${ }^{9}$. Fato idêntico ocorria nos lugares de uso frequentados com Newman e, por isso, as notas eram escritas após retorno do campo, juntamente com as transcrições das gravações, nos casos em que foi possível utilizar o telefone celular ou outro dispositivo para realizá-las, isto permitiu um processo rico de rememorar, elaborar e escrever.

\section{Participando de roda de crack em uma "biqueira"}

Quando começamos a participar das rodas de crack, percebemos que nossa presença como não usuário era em si um constrangimento, só superável no futuro por uma postura mais próxima possível do participante observador. Havia um certo pudor, perceptível em algumas pessoas, de usar crack quando nos encontrávamos no local. Apenas tempos depois ficou claro, pela pesquisa de campo, um dos valores importantes entre usuários de crack: não fazer uso em frente ao "Zé povinho" ${ }^{10}$. Não dar espaço para a maledicência, a crítica e o olhar reprovador, assim como não demonstrar ser desrespeitoso com quem não fuma, sendo agressivo ao exibir o consumo do crack, principalmente ao tratar-se de crianças.

Ao nos dirigirmos com Newman, após contatos iniciais em que ele pôde demonstrar as técnicas de manipulação da droga e nos quais vivenciamos seu consumo coletivo, para certo local de comércio e uso de crack com uma quantidade significativamente maior de pessoas que os visitados inicialmente, temos um importante impacto. Porém, hesitações e medos começam a se dissipar conjuntamente com o maior convívio com os interlocutores. Passamos a experimentar uma contínua e segura dissolução das noções preconcebidas até sua inversão rumo a uma maior identificação e reconhecimento dos valores morais, estéticos, gostos e preocupações, enfim, dos

\footnotetext{
${ }^{9}$ Chegamos a ser advertidos por um frequentador do bar onde nos posicionáramos sobre o sério risco de sermos confundidos com policial, caso continuássemos a escrever em nossa caderneta de campo.

${ }^{10}$ Termo utilizado para designar os não usuários de crack em atitude julgadora com relação aos craqueiros. 
sentimentos próprios deste estilo de vida, desta parte desprezada de nossa cultura popular: a cultura do uso do crack.

Não foi tão simples permanecer no ambiente da observação participante. $\mathrm{Na}$ "biqueira" com fumódromo fica usuário e "vapor"11. Ir apenas observar e estar com eles é uma intromissão, causa desconforto, insegurança quando não franca hostilidade ${ }^{12}$. Fica patente a relevância de Newman (nosso interlocutor e guia) como facilitador no acesso e socialização na "biqueira". Também nos começa a aparecer com maior clareza a importância ética de manter a revelação de nosso papel de pesquisador sob a responsabilidade do interlocutor, do nativo, afinal, trata-se de sua segurança no campo durante e após o término de nossa pesquisa. Qualquer atitude irresponsável e voluntarista por parte do etnógrafo poderia colocar as amizades, reputação e mesmo a vida de nosso interlocutor e guia na introdução ao campo em risco. Contudo, em todas as situações de pesquisa, o papel de pesquisador sempre pôde ser revelado em seu devido tempo. Mesmo com as precauções de Newman, na primeira noite em certa "biqueira", uma frequentadora do barraco em que nos encontrávamos alojados iria incomodar-se com o fato de alguém estar lá sem fazer uso do crack como todos os outros. Isto geraria uma reclamação à "contenção", a quem fôramos apresentados na chegada a "biqueira", e ele viria nos ameaçar com uma faca dentro do mesmo barraco.

\section{A empatia, o crack e a interlocução}

Chegamos a transportar certo interlocutor que se encontrava no intuito de ir a local de comércio de aparelhos celulares roubados. Contribuir para a venda de produto de roubo, certamente é crime e possui suas implicações legais e éticas; possivelmente não o teríamos levado caso tivessemos todas as informações: primeiro de tratar-se de produto deste tipo e segundo de estarmos nos dirigindo à Praça da Sé, para lá, efetuar a transação. A princípio estaríamos apenas "dando um cavalo", ou seja, uma carona. Contudo, sem acompanhar os nativos, como cumprir o imperativo do ofício de antropólogo legado por Malinowski? ${ }^{13}$

Os etnógrafos não dispõem de orientações suficientes no momento de fazerem suas opções éticas em pesquisas com interlocutores cujas atividades incluem atos de

\footnotetext{
${ }^{11}$ Responsável pela venda de drogas em uma "biqueira".

${ }^{12}$ Portanto, como fez Malinowski, cada vez mais: "Tive de aprender a comportar-me como eles e desenvolvi certa percepção para aquilo que eles consideravam como ‘boas' ou 'más' maneiras.” (MALINOWSKI, 1978, p. 22)

13 "Por outro lado, neste tipo de pesquisa, recomenda-se ao etnógrafo que de vez em quando deixe de lado máquina fotográfica, lápis e caderno e participe pessoalmente do que está acontecendo.” (MALINOWSKI, 1978, p. 31)
} 
violência. (MACRAE; VIDAL, 2006) Procedimentos como a assinatura de atestados de consentimento se tornam surreais com pessoas procuradas pela polícia, por exemplo. Como a própria inserção no campo é negociada, os diálogos posteriores seriam consentidos por definição (OLIVEIRA, 2004). Não faz sentido consentimento para a autoincriminação. Enfim, esta papelada para proteção aos seres humanos tem por objetivo mais a salvaguarda das instituições de pesquisa e menos os sujeitos pesquisados, em seus interesses e dignidade (BOURGOIS; SCHONBERG, 2009).

Turnbull (1986) observou sobre o trabalho de campo que ele nos propicia oportunidade para rever nossas próprias ideias e valores, nosso próprio ser. Durante a etnografia voltamo-nos para nós mesmos e abandonamos o antigo, estreito e limitado self, para enfim descobrirmos um novo eu mais apropriado ao contexto. A companhia dos usuários de crack seguiu sendo, em todo período de trabalho de campo, a mais prazerosa e instigadora das interlocuções. Necessitávamos estar com eles para a pesquisa de campo e desejávamos estar em sua presença pela oportunidade de discutir o tema de nossa paixão intelectual naquele momento - o uso coletivo na roda de crack. Com nenhum outro grupo, mesmo os acadêmicos, esta questão pôde ser tão bem compreendida, vivida e compartilhada. Sentar em sua companhia no cotidiano de suas atividades não se apresentou como diferente de fumar com eles. Em uma roda de crack, fuma-se. No cotidiano se faz um "corre", ou um "peão", se está ou não se está junto na "caminhada". ${ }^{14}$ Eles definitivamente estiveram juntos conosco em nossa caminhada etnográfica, a ponto de podermos compartilhar e discutir partes do texto que viria ser a tese de doutorado. $\mathrm{O}$ que fez com que "estar aqui", entre os acadêmicos, e "estar lá" (OLIVEIRA, 1998, p. 25), no campo, se confundissem durante o processo de escrita. As conversas com nossos interlocutores foram muito mais constantes, importantes e estimulantes que as desenvolvidas entre pares, na comunidade acadêmica. Como se em contato com nossos interlocutores a discussão também ocorresse quase como entre pares.

Para um debate sobre a oposição entre "experimentar lá" e "escrever aqui", outra questão se coloca: a de pensar a relação entre pesquisador e seus interlocutores como dispositivo central de construção do saber antropológico. Juntos, na "caminhada", nos tornamos "parças" ${ }^{15}$, e esta relação pode ter papel fundamental na construção do tipo de conhecimento antropológico que nos interessa. Daquele que toma as atitudes de

\footnotetext{
14 “Corre", "peão" e "caminhada" são termos nativos fundamentais para se iniciar o trânsito na cultura do crack. São três dimensões do movimento.

${ }^{15} \mathrm{O}$ mesmo que parceiros ou colegas.
} 
observador e observado como análogas, ou "reversas" (WAGNER, 1981). Pois afinal, o estudo da cultura, cultura é. Como na improvisação do jazz, todo ser humano inventa cultura e tínhamos a certeza íntima de que eles, a todo tempo, teciam considerações, elaboravam sobre nossa presença ali.

O ofício antropológico propõe a criação de uma narrativa a respeito do outro, que parte das relações construídas no campo. Quando se adentra na intimidade cultural nativa (HERZFELD, 1997) como procuramos fazer, certos relacionamentos passam a ser constantemente negociados. O tipo e profundidade das informações que daí irá surgir dependem e mesmo provém, grandemente, da qualidade destas relações. Antes de obter informações a respeito das relações entre nossos interlocutores, construímos relações com eles. É um movimento que vai das relações com eles para o saber sobre as relações entre eles (STRATHERN, 1999). Relacionar-se com usuários de crack e ser seu interlocutor foi fazer parte da "caminhada", seu modo fundamental de habitar a terra (INGOLD, 2015[2011], p. 38).

Para a construção de um discurso que se pretenda simétrico (LATOUR, 1994), que não se coloque como superior ao discurso nativo, quanto mais intensamente afetado fôssemos pelas relações proporcionadas pelo campo e, principalmente, pelas mesmas forças que atuam sobre eles, naquilo que para nós era o campo e que para eles era a vida; mais nos foi permitido sentir, não a sensação no outro, mas em nós, as consequências de estar na mesma posição do interlocutor (FAVRET-SAADA, 2005). A partir deste encontro, a escrita etnográfica pode se dar de modo mais profícuo. Quando aceitamos participar ativamente na roda de crack, era atrás disto que estávamos, de impregnar-nos da fumaça proveniente da pedra dentro dos barracos dispostos na "biqueira" sob as mesmas condições de sujeição às intempéries do clima: o frio cortante de julho e o calor abrasador do primeiro mês do ano; e sob as ameaças da polícia de quem tivemos de nos esconder juntamente com nossos "parças”. Porém, cremos que consumir crack vá além da afetação de que nos fala Favret-Saada.

Pesquisadores(as) das tradições ayahuasqueiras fizeram uso do chá durante suas etnografias (cf. GROISMAN, 2000). Não faz sentido aos praticantes dos cultos que incluem o Santo Daime, por exemplo, que pessoas que não ingeriram o chá participem das cerimônias. Caso se queira acessar, por um período razoavelmente longo, os rituais onde o Daime é bebido fica quase como uma imposição consumi-lo. Algo semelhante ocorre 
com os rituais de consumo do "bloco"16 ou rodas de crack. Para fazer parte delas, se fuma. Isto permite um rico compartilhar de experiências. Não apenas sobre a "brisa" ${ }^{17}$, mas sobre a "caminhada" de cada um ${ }^{18}$. Para o usuário de crack que vive nas ruas de São Paulo, mais importante que discorrer sobre os efeitos da droga é falar sobre a vida.

Pudemos sentir o quanto o crack é empatogênico sob condições ambientais adequadas e o prazer provocado pela conversação sob seus efeitos. O que ocorria era um excesso de discurso, tanto do nosso interlocutor quanto do antropólogo. Energizados pelo consumo da pedra e possuindo histórias de vida que podiam encontrar experiências comuns disponíveis para comparação, chegávamos a disputar espaço na conversa para dizer o que tínhamos vontade de falar. O que fizemos foi procurar nos controlar para dar mais espaço ao outro, reprimir um pouco a propensão a confessar-nos ${ }^{19}$ no lugar deles, que também punham-se inquietos no afã de se expressar. Nossa relação com o ponto de vista nativo ${ }^{20}$ se deu, geralmente, desta maneira entusiasmada; e os diálogos transcorriam por efeito de manifestações puramente corporais deste entusiasmo. Em que nosso discurso pôde guardar um certo aspecto de observação experiencial, não pela "descrição das mirações que vivenciei”21, mas por aspectos de nossa vida que compartilhamos com os "parças" e que jamais havíamos dito a quem quer que seja. Certamente, por nunca os ter podido elaborar e pronunciar sem a empatia que o uso do crack proporciona.

Malinowski (1978) fornecia tabaco aos trobriandeses em troca de permissão deles às suas investidas sobre os assuntos tribais e a fim de estar em posição de fazer boas questões e obter boas respostas. Gerald Berreman (1962), em sua pesquisa no norte da Índia, valeu-se dos serviços de um intérprete abstêmio de álcool e não comedor de carne, três meses se passaram e seu intérprete adoeceu sendo substituído por um muçulmano bebedor de álcool e comedor de carne. Apenas então, Berreman pôde saber do costume de se realizarem festas intercastas com bebidas alcoólicas e carne. O acesso a informações dos

\footnotetext{
${ }^{16} \mathrm{O}$ mesmo que pedra de crack.

${ }^{17}$ Efeitos do crack

${ }^{18}$ Nas experiências pessoais que tivemos com a ayahuasca, quanto mais elaborado fosse o ritual menos confortável sentia-nos em participar. Estar naquela cerimônia religiosa, cercado por outros homens que desenhavam uma dança sobre o chão cimentado, fazia-nos experimentar imenso sentimento de inadequação. Nos sentíamos francamente ridículos. O inverso ocorreu na roda de crack com moradores de rua, muitos com passagem pelo sistema prisional e outros que haviam acabado de cometer delitos. Ali, em uma espécie de retorno aos tempos de uso pesado de cocaína cheirada, pudemos desfrutar de uma atitude genuinamente fraterna e da sensação de estar entre os nossos. Como a que nos fazia retornar sempre à "boca" (local de comércio e uso de drogas) mais de uma década atrás.

${ }^{19}$ Como nos ensinou Foucault (2003, p.58), os processos de individualização pelo poder teriam tornado o homem ocidental um "animal confidente".

${ }^{20}$ Isto, não significa assumir o ponto de vista do usuário de crack, ou buscar algo oculto por trás de suas práticas, mas construir um ponto de vista a partir do ponto de vista da nossa relação com o ponto de vista nativo. (VIVEIROS DE CASTRO, 2002)

${ }^{21}$ Como no caso do estudo dos rituais da Barquinha e o consumo de Ayahuasca feito por Marcelo S. Mercante (2015, p. 56).
} 
mais variados tipos só foi aberto após os moradores saberem da ocorrência de ocasiões de uso da bebida alcoólica local em sua casa. Após transportarmos o "vapor" algumas vezes, ele passou de modo insistente a pedir para guiar o carro e tivemos de encontrar formas de recusar sem ofendê-lo, da mesma maneira como negamo-nos a dirigir pela contramão e conduzir de modo espetacular como acabou nos sendo pedido. Os limites da atuação do antropólogo em campo foram cotidianamente colocados em questão.

\section{A importância da confiança conquistada no campo}

A prática da "treta" 22 sempre foi uma constante nos ambientes de consumo do crack que frequentamos; ficar alheio a ela não se mostrou uma opção realista. Certamente, envolver-se nas trocas levanta um problema ético. A troca, como elemento fundamental de inclusão e exclusão de indivíduos na comunidade de usuários de drogas foi amplamente debatida em pesquisa com consumidores de heroína nos Estados Unidos. Os antropólogos detectaram que a comunidade de usuários se mantinha através de uma economia moral das trocas (BOURGOIS; SCHONBERG, 2009), esta economia os envolvia em uma rede de relações mútuas e definiam os limites da comunidade. Ou seja, faz parte quem troca. Não trocar é ser antissocial e arriscar-se a ser levado ao ostracismo. Os autores preocuparamse em não comprar informações, ou tornarem-se patrões, mas não poderiam ficar alheios à forma corriqueira (troca de alimentos, dinheiro e drogas) de definir e expressar amizade, organizar hierarquias e excluir outsiders indesejáveis. Tiveram de aprender quando dar e quando negar, e concluem com a importante constatação da inadequação das regras mais dogmáticas de pesquisa à realidade das ruas.

Roberto Cardoso de Oliveira (2004) ao criticar a Resolução n. ${ }^{\circ}$ 19/96 da Comissão de Ética em Pesquisa do Ministério da Saúde para regular os aspectos éticos das pesquisas com seres humanos discorda da extensão das preocupações com as pesquisas biomédicas para a antropologia, isso teria ignorado a realização por parte desta última, de pesquisas com observação participante entre populações ocultas, além de ignorar a diferença entre pesquisas em seres humanos (caso da área biomédica) e com seres humanos (situação da antropologia social e cultural). O paradigma da primeira é a relação com cobaias, da segunda, com interlocutores, neste caso, marcado pela negociação nos mais variados aspectos das interações ocasionadas pela incursão do antropólogo no campo, onde até o próprio objeto da pesquisa será negociado.

\footnotetext{
${ }^{22}$ Troca generalizada de bens e serviços.
} 
$\mathrm{Na}$ antropologia, os sujeitos da pesquisa são antes concebidos como pessoas, entidades socioculturais e a questão ética posta nesta relação de alteridade marcada pela diferença é o respeito por seus costumes, comportamentos e práticas (CAROSO, 2004). É inevitável ao pesquisador de comportamento desviante, sujeito a sanções na forma da lei, infringir certas leis (BECKER, 2008). Sabemos ser da Lei n. ${ }^{\circ}$ 11.343/06 a penalização para quem "induzir, instigar ou auxiliar alguém ao uso indevido de drogas", em seu Artigo 33, parágrafo 2 (BRASIL, 2006). Ficaria assim vedada, a postura tolerante nas pesquisas com usuários de drogas em relação às suas práticas, tanto quanto a convivência com estes interlocutores que demanda a participação em atos ilegais (MACRAE; VIDAL, 2006).

Após alguns anos de pesquisa de campo, o sociólogo William Foote Whyte veio a escrever o clássico da sociologia Sociedade de Esquina e nesta obra, apresenta e analisa a organização social e a cultura dos jovens ítalo-americanos de um bairro apelidado por ele de Cornerville, no Boston's North End. Residiu e participou ativamente da vida social e política da comunidade italiana daquele bairro, chegando a fazer parte de clubes e sendo eleito para ocupar cargos de certa importância. Para ele, apenas dar uma volta com os rapazes de Cornerville não era suficiente para fazer uma pesquisa sobre a sociedade de esquina. Era necessário saber quais perguntas deveriam ser feitas e quando poderiam acontecer (WHYTE, 2005[1943]), mas em todo caso, se fazia necessário dar uma volta. Fazer etnografia com consumidores de crack é dar muitas voltas com eles; participar de suas "caminhadas" empreendidas, geralmente, sob o efeito de uma droga que chegou a ser caracterizada, por um de nossos interlocutores, como possuidora de um "espírito andarilho”. Não é razoável que se creia ser possível caminhar acompanhado na cidade, por seguidas vezes e em ambiente quase sempre hostil, sem um mínimo de aceitação com o que é feito, inclusive o consumo do crack.

A realização de um trabalho etnográfico significa a escolha por opções de comportamento e cumplicidade no campo (VAN MAANEN, 1983), escolha do que será ou não publicado, não havendo como não desagradar alguém por tratarem-se sempre de opções a serem feitas entre alternativas que agradam uns em detrimento de outros. Nossa escolha pela participação em práticas tornadas ilegais pela legislação proibicionista foi, em parte, facilitada por um histórico pessoal de vivência das mesmas práticas; e a escrita foi fortemente influenciada pelas escolhas feitas durante o trabalho etnográfico. 
Ler a respeito da experiência etnográfica não é passar por ela, não é dar um "trago" 23 nas margens quase inacessíveis do viaduto. O mundo a se entrar como leitor, não é a experiência direta da vida nas esquinas da sociedade, estando o autor engajado na interpretação desta, como reconstrução, inscrita no texto, assim, o texto produzido não pode determinar como seus leitores irão interpretá-lo (ATKINSON, 1990). Contudo, se deve tomar o cuidado para não produzir nos leitores um efeito inverso ao pretendido, isto é, cabe o esforço por apresentar nossos interlocutores em toda sua dignidade, como pessoas interessantes, inteligentes e plenas no domínio de sua vontade. Pretendemos, sempre, contrapor-nos ao discurso midiático de "culpabilização das vítimas" (MACRAE, 2013, p. 7), mas sabemos também que, infelizmente, ao tomar contato com os dados colhidos no campo, pela leitura de uma etnografia, o leitor está livre para interpretá-los do modo mais negativo possível e terminar a leitura mais convencido de seus preconceitos e igualmente engajado na produção da morte social dos usuários de crack.

William Foote Whyte (2005[1943]) orientou a relação com seus interlocutores no campo pelo que designou como reciprocidade interpessoal. Acreditava ter podido ser em campo tão útil ao seu interlocutor e guia quanto este foi ao observador participante. Esta posição foi duramente criticada, inclusive pelos descendentes de seu informante-chave, que vieram a posicionar-se pela injustiça cometida contra seu pai que deveria ter sido coautor do estudo que muito contribuiu para produzir - e que rendeu fama, prestígio e dinheiro para Whyte. Também houve críticas pelo fato do texto publicado não ter sido discutido previamente com os membros da comunidade estudada. Whyte defende-se e observa que tais preocupações não estavam presentes no final dos anos trinta, quando se desenvolveu o estudo; e que levar suas conclusões de volta ao campo poderia ter causado constrangimentos entre os envolvidos. Portanto, o que se pode tirar das polêmicas em torno deste autor clássico é que devemos tomar um cuidado extremo em não projetar necessidades acadêmicas momentâneas, por mais interessantes que possam parecer, sobre nossos interlocutores.

Conquistar o mínimo de confiança em campo pode ser crucial para o trabalho etnográfico; como ele se dá sob condições impostas, na maior parte das vezes, pelos nossos interlocutores, demonstrar o máximo de sinceridade possível sobre nossas intenções em campo, e, porque não, de nossas dúvidas e mesmo angústias relacionadas a pesquisa, possa ser o meio de chegar a uma relação mais justa e simétrica. No momento em que passamos

\footnotetext{
${ }^{23} \mathrm{O}$ mesmo que fumar crack
} 
a frequentar o campo sem a companhia de nosso guia das primeiras incursões, precisamos rapidamente desenvolver algumas habilidades que foram surgindo na medida que se mostravam eficazes. Conseguir um espaço na conversa para falar o máximo possível a respeito das intenções quanto a pesquisa foi uma destas habilidades que mostrou servir como uma forma de apresentar-nos em ambiente onde a desconfiança é plenamente justificável. Certa feita, pudemos perceber o quanto as desconfianças diminuíram depois de bem esclarecida a identidade como antropólogo, o programa de pós-graduação de origem, quem era o orientador e mais algumas considerações sobre lembranças comuns do bairro de Ondina em Salvador. Esta conversa fez com que o interlocutor sentisse a necessidade de guiar-nos por outros ambientes de consumo de crack para que a pesquisa não ficasse, na sábia visão dele, pouco abrangente. Também passa a aconselhar a não fumar crack e a discorrer sobre como poderíamos ser explorados, segundo seu ponto de vista, por outros usuários na rua ${ }^{24}$.

Ao demonstrar-nos éticos e corretos, ele aparentemente sentiu-se obrigado a agir de modo recíproco; a ponto de tecer uma recomendação foi sobre nossos trajes. Deveriam ser mais modestos a fim de não chamar a atenção da polícia sobre nós, eles poderiam resolver nos proteger do usuário de crack com a aparência de morador de rua. Michael Agar (1980) em sua pesquisa com usuários de heroína nova-iorquinos foi energicamente compelido por eles a adaptar-se ao seu modo de vida para não os colocar em risco. Para estar com nossos interlocutores é preciso não os comprometer com a polícia, dominar alguns códigos, certas posturas e não ser descuidado, ou "vacilar" em meio a uma atividade ilegal. Philippe Bourgois (2003) comenta suas dificuldades de homem branco em El Barrio, região de Nova Iorque e local de sua pesquisa. Como era frequentemente abordado pela polícia por suspeita de ser um usuário em busca de drogas, ou simplesmente um otário perdido em local inapropriado a alguém de seu status, Bourgois, em sua pesquisa com usuários de crack, teve nos constrangimentos legais, sua preocupação mais imediata. A simples presença dos pesquisadores foi cogitada por ele como algo possivelmente perigoso aos usuários de drogas.

Contamos com as possibilidades abertas pela presença de Newman no início da investigação, somadas à disposição em frequentar os locais de uso, os territórios psicotrópicos sob a fumaça constante, no beco, este espaço ao mesmo tempo, ponto de

\footnotetext{
${ }^{24}$ Isto poderia nos permitir pensar no ponto de vista dos usuários sobre eles mesmos e seus pares, em como passam a internalizar a visão negativa construída, principalmente, pela mídia sobre eles. A existência na rua vai formando, com exemplos retirados de histórias repetidamente contadas e experiências vividas, uma imagem do sujeito ardiloso, repleto de conhecimento sobre como sobreviver na cidade, a partir de algumas estratégias com certo nível de trapaça.
} 
mercado e ponto de consumo (FERNANDES; PINTO, 2004). Newman viabilizou a presença no campo com chances de acompanhar práticas, e certamente, discursos e racionalizações provenientes dos interlocutores, de certa forma mais próximos à condição de "parceiros". Da tensão inerente ao trabalho etnográfico, entre mais observar ou mais participar, se pode concluir que, na pesquisa empreendida, caso o papel de observador se destacasse em relação ao de participante, teríamos de dispor de muito mais tempo para conseguir atingir a condição de "parceiro". Na etnografia da antropóloga Luana Silva Bastos Malheiro (2013), em região do centro velho de Salvador/BA, ela valeu-se de sua condição de redutora de danos para aproximar-se dos usuários, porém, demandou um período de oito meses de contato até poder presenciar as ocasiões de uso. O trabalho de Bruno Ramos Gomes e Rubens Adorno sobre as trajetórias de usuários de crack no centro de São Paulo também se aproveitou da condição de profissional atuante em redução de danos do primeiro, como modo de acessar o campo (GOMES; ADORNO, 2011). Em sua pesquisa sobre uso de crack entre prostitutas da região da Luz, no centro de São Paulo, Selma Lima da Silva utilizou-se da companhia de membros da Pastoral da Mulher Marginalizada da Arquidiocese de São Paulo e precisou vencer a resistência destes à pesquisa (SILVA, 2000). Caso extremo foi uma pesquisa de doutoramento em antropologia social com o trabalho de campo integralmente mediado por programas de redução de danos (RUI, 2012). A pesquisadora passou sete meses em negociações com o programa para visitar locais de uso na cidade de Campinas, no estado de São Paulo, e não estava autorizada a fazê-lo sozinha. Também lhe foi vedado o uso de gravador e "algumas perguntas jamais puderam ser feitas" (RUI, 2012, p. 35). Ficou totalmente restrita aos horários, contatos e trajetos das equipes de redutores. Era-lhe até proibido levantar os históricos de uso de drogas e chegou a ser diversas vezes repreendida por seu comportamento como "redutora". Mesmo nestas condições, ir para o campo sozinha sequer foi cogitado pela futura doutora em antropologia, apesar de afirmar ter destreza para circular nestes espaços por sua experiência pregressa como "educadora de rua”. Os usuários foram considerados uma "população de difícil acesso" e a pesquisa sem estas “instituições legitimadas" seria "quase inviável”. ${ }^{25}$ Desta perspectiva, a autora pretendeu estudar o consumo abusivo realizado, segundo ela, por uma pequena parcela dos usuários e reconhece ter conseguido dados de qualidade apenas "razoável”. ${ }^{26}$

\footnotetext{
${ }^{25} \mathrm{O}$ inverso pode ser dito dos redutores de danos com quem ela diz compartilhar experiência educacional e gostos por viagens e profissionais.

${ }^{26}$ A autora decidiu pela pesquisa com o tema do abuso do crack e não sobre o trabalho das equipes de redutores, um contraponto à pesquisa anterior da antropóloga sobre comunidades terapêuticas, após perceber o apelo do tema do uso cadernos de campo, São Paulo, vol. 27, n.1, 2018
} 
Um trabalho etnográfico sobre uso de drogas injetáveis na região central de São Paulo, com interlocutores de classe média e outros provenientes do lumpesinato, foi levado à frente por Osvaldo Fernandez, entre o final dos anos 1980 e início da década de 1990. O estudo contempla práticas "pesadas" entre usuários socialmente distantes do antropólogo, observados nas cenas de uso. ${ }^{27}$ Este, tanto quanto o de Luana S. B. Malheiro (2013), se assemelha mais ao tipo de pesquisa de campo sobre drogas que desenvolvemos.

\section{O uso do gravador, prejuízos à saúde e convivência familiar}

Observamos diversas vezes a disposição dos usuários de crack, frequentadores de um mesmo local de uso e convivência, em comentar sobre os acontecimentos locais. Certa feita, após esclarecido o papel de pesquisador a um casal de interlocutores e feito observações sobre a necessidade de manter-se sigilo sobre estarmos realizando uma pesquisa de cunho antropológico, percebemos, em nossa visita posterior ao campo, a indiscrição de nossos parceiros. O "vapor" que trabalhava no local, ao conversar conosco em seu barraco, na presença de sua companheira e coordenadora da "biqueira", veio questionar-nos se seríamos algum jornalista, como quem já houvera sido informado de algo. Pergunta se estaríamos gravando a conversa.

Importante observar que nas visitas anteriores ao campo havíamos feito uso de celular para proceder às gravações, porém, o aparelho, se visível, causava imediata agitação, rapidamente tínhamos de colocá-lo em local não visível. Este tipo de aparelho é moeda de troca na "biqueira". Também seria impossível o uso de caderneta de campo, estas ferramentas para registrar dados incomodam, assim como perguntar demais também pode "roubar a brisa" ${ }^{28}$ de alguém, fazê-lo (a) "perder o trago" 29 . Assim, adquirimos outro tipo de gravador, mais discreto, na esperança de causar menor impacto visual nos ambientes de uso. Um pen drive mostrou-se muito apropriado, o usamos sempre após consulta aos presentes, porém, possivelmente por suas dimensões reduzidas causava menor

\footnotetext{
do crack. Ou nas palavras dela: "Mais uma vez, enfatizo que o tema central, o consumo de crack, acabou se impondo durante o trabalho: não só porque tive mais contato com usuários dessa substância devido ao acompanhamento das atividades dos programas de redução de danos, mas também e sobretudo, porque durante a pesquisa o crack acabou ganhando notoriedade inesperada". (RUI , 2012, p. 45)

27 "A outra rede de entrevistados poderia ser conceituada como lumpesinato: sem remuneração/moradia fixa, com baixo grau de escolaridade, composta de dois travestis, dois presos, um homossexual e um bissexual. Os travestis trabalham na prostituição de rua, sendo um deles paciente de Aids na casa de apoio Brenda Lee. Na segunda rede de usuários percebemos, quando comparado com a rede de classe média, um número maior de pessoas com problemas com a lei, prisões e com mais casos de HIV/Aids. Nessa última rede também há um número maior de indivíduos que recorreram a tratamentos psiquiátricos e psicológicos”. (FERNANDEZ, 1997, p. 104)

${ }^{28}$ Interromper os efeitos desejados do crack

${ }^{29}$ Deixar de aproveitar os efeitos oriundos de uma unidade de consumo da pedra de crack, geralmente, em São Paulo, sua sexta parte.
} 
desconforto aos usuários de crack e logo era esquecido. O certo é restringir sua utilização à concordância dos interlocutores e após o esclarecimento sobre nosso papel de pesquisador. Outro procedimento se assemelharia a espionagem. Mesmo assim, devemos ressaltar que uma roda de crack em local de tanta densidade social quanto uma "biqueira" não está sob nosso controle. Muito pelo contrário, o antropólogo é quem deve se submeter, e com grande atenção, às regras próprias da etiqueta "craqueira". Dito isto, salientamos que é inviável controlar quem entra e quem sai da roda de crack e, muito menos, ter a consciência dos riscos que cada um traz à segurança dos que lá estão.

Nada neste campo é simples. Chegamos a presenciar fatos muito comprometedores à segurança, tanto nossa, quanto dos interlocutores. Como, por exemplo, o "resumo da biqueira": situação tensa de contagem do dinheiro e acerto de contas entre a coordenadora, os "vapores" e um responsável da "Estudantes", como eles chamavam a "biqueira" localizada na rua dos Estudantes (São Paulo/SP) provedora dos "blocos" comercializados no local de uso de crack que frequentávamos. Ao chegar para dar início a contagem das notas e realização das contas, o enviado da "Estudantes" nos encarou de modo desconfiado por alguns segundos, com seu rosto a uma distância de um palmo aproximadamente, só com a intervenção de Newman, ele se acalmou.

Chegamos a experimentar crack nos anos 1990, em um contexto de esgotamento das fontes fornecedoras de cocaína em pó, após certa hora da madrugada. Não pareceu fazer nenhum efeito digno de nota e a experiência não se repetiu. $\mathrm{O}$ abandono do uso do álcool acompanhado de cocaína deu-se após período de internação em clínica de recuperação e frequência a reuniões dos Narcóticos Anônimos. Mais de 13 anos depois, novo contato com a substância. Qual o risco de tornar-nos usuário pesado novamente? Difícil dizer. Há algo diferente no atual uso, significativo o suficiente para permitir ter esperanças de resultado diverso do modo anterior? Aparentemente, sim. O propósito de uso parece ser a maior diferença. Há o propósito claro em estar com eles; fazer uma etnografia, produzir uma tese de doutoramento em antropologia social, base para o início de uma carreira profissional como antropólogo.

Além de termos sido "adicto em recuperação" ${ }^{30}$, éramos asmáticos em tratamento. As incursões ao campo, respirar a fumaça, tragar, levaram a muito significativa piora dos sintomas. Iniciamos novo tratamento e uma série de medidas profiláticas no ambiente

${ }^{30}$ Termo usado pelos Narcóticos Anônimos àqueles em permanente busca por recuperar-se da compulsão e obsessão pelo uso de drogas. 
doméstico. Até onde prosseguir? "Não faça nada com que não possa conviver, profissionalmente e pessoalmente" (BERNARD, 2008, p.376), este conselho dado ao comportamento sexual no campo poderia servir também a outros limites do corpo do etnógrafo.

Do nosso corpo ao corpo do outro e à convivência familiar. Fazer campo junto à população tão estigmatizada e em ambiente repleto de representações negativas construídas pela mídia constitui desafio ao convívio familiar. Na prática, é retornar ao lar, rever esposa e filha após estar sentado sobre chão coberto de urina, em meio a ratos, na companhia de traficantes e pessoas que realizam pequenos furtos e roubos. É ir dormir depois de vivenciar alguém lhe mostrar uma faca, de se esconder da polícia e, principalmente, chegar em casa com os olhos "esbugalhados" pela inalação da fumaça, ou pelo "trago". Isto tudo poderia ter tido maiores consequências para a vida conjugal e familiar, como foi para P. Bourgois após o término de sua pesquisa em El Barrio que coincide com o fim de seu casamento (BOURGOIS, 2006).

O problema ético insolúvel deste tipo de abordagem, na opinião de Zinberg ao tratar em seu clássico Drug, set and setting do uso controlado de substâncias psicoativas como a heroína, é a possibilidade de nossas considerações levarem alguém a usar a droga e vir a ter problemas posteriores, esta preocupação parece caber de certa forma em nossa pesquisa. Para Zinberg, demonstrar o uso controlado, além de combater estereótipos, serviria à construção e reforço de outras possibilidades de uso, além do pesado. Ele reconhece o modo como sua pesquisa acaba sendo posicionada no debate público a respeito das drogas e o problema ético. Na mídia e até em ambientes profissionais e por que não dizer acadêmicos também, o show precisa ser "balanceado", um entrevistado, ou palestrante pró-drogas e outro antidrogas. Nestes espetáculos, posicionados pela proibição e abstinência; qualquer oposição ao proibicionismo é percebida como pródrogas. Não pretendemos fazer um discurso pró-crack, mas sim, pró-“craqueiro”.

Acima de tudo, existia um problema ético para Zinberg: declarar que algumas pessoas são capazes de controlar seu uso de heroína. Pois, é possível que esta informação pudesse levar algum indivíduo a usar a droga, sem estar preparado devidamente e em condições de lidar com isso. ${ }^{31}$ Não tratamos especificamente de uso controlado de crack, como fez Zinberg com a heroína, nossa pesquisa busca, contudo, um ponto de vista fora

\footnotetext{
${ }^{31}$ Quando se verificou que o uso controlado era praticado por diversos usuários, percebeu-se que a descoberta tinha de vir ao conhecimento público, este deveria ser alertado do fato de o uso ocasional de heroína ser também um padrão estável, tanto quanto o abusivo.
} 
dos estereótipos. Os usuários não são zumbis, são pessoas interessantes, inteligentes e devem ser respeitadas em seu de estilo de vida, este é nosso posicionamento. A objetividade vem do respeito ao bom método de coleta, análise e escrita. O quanto isto poderia encorajar outros a fumar crack? Esta pergunta não tem resposta. Resta-nos apostar, como Zinberg, no reforço a padrões de quem usa sem se deixar usar pela droga, como é característico ouvir no discurso nativo.

\section{Considerações finais}

Ao decidir-nos pela publicação deste artigo, temos em mente o propósito de contribuir com duas questões que ao nosso ver carecem muito de sistematização, e não temos a pretensão de oferecer uma versão completa disto, que são as questões metodológicas e técnicas do trabalho etnográfico em cenas de uso de crack; e a ética nestas mesmas condições de pesquisa.

Esperamos que fique no leitor(a), ao término da leitura do artigo, clara nossa posição frente a necessidade, e mesmo as vantagens, de se tomar o usuário de crack como detentor do conhecimento mais acurado sobre suas condições de vida - e poderia ser diferente? Acreditamos que não e vamos além. Nutrimos o sincero propósito de provocar, naqueles que nos derem a honra de sua atenção, ao menos a indagação quanto à pertinência de se considerar os usuários de crack também como bons parceiros na produção de conhecimento acadêmico a respeito deles mesmos. Isto feito, o artigo terá cumprido a tarefa que lhe conferimos.

\section{Referências Bibliográficas}

AGAR, M. Getting better quality stuff: Methodological competition in an interdisciplinary niche. Urban Life 9, 1980. pp. 34-50.

ALMEIDA, M.; EUGENIO, F. Paisagens existenciais e alquimias pragmáticas: uma reflexão comparativa do recurso às "drogas" no contexto da contracultura e nas cenas eletrônicas contemporâneas. In: LABATE, B. C.; GOULART, S.; FIORE, M.; MACRAE, E.; CARNEIRO, H. (orgs.), Drogas e cultura: novas perspectivas. Salvador: EDUFBA, 2008. pp. 383-408.

ATKINSON, P. Introduction: Ethnography as a method and as a genre. In: The Ethnographic Imagination: Textual construction of reality. London \& New York: Routledge, 1990.

BECKER, H. S. Outsiders: estudos de sociologia do desvio. Rio de janeiro: Jorge Zahar, 2008 [1963]. 
BERNARD, H. R. Participant Observation. In: H. R. BERNARD, Research methods in anthropology : qualitative and quantitative approaches. New York: Altamira Press, 2008. pp. 342-386.

BERREMAN, G. D. Behind many masks. Ithaca, N.Y.: Society for Applied Anthropology, 1962.

BOURGOIS, P. In search of respect: selling crack in El Barrio. Nova Iorque: Cambridge University Press, 2006.

BOURGOIS, P. \& SCHONBERG, J. Righteous dopefiends. Los Angeles: University of California Press, 2009.

BRASIL. Lei no 11.343, de 23 de Agosto de 2006. Institui o Sistema Nacional de

Políticas Públicas sobre Drogas - Sisnad; Brasília: Ministério da Justiça, 2006.

FAVRET-SAADA, J. Ser afetado, Cadernos de campo, no 13, 155-161, 2005.

FERNANDES, L., \& PINTO, M. El espacio urbano como dispositivo de control social: territórios psicotrópicos y políticas de la ciudad. Uso de drogas y drogodependencias, 2004. pp.147-162.

FERNANDEZ, O. Coca light? Usos do corpo, rituais de consumo e carreiras de "cheiradores" de cocaína em São Paulo. Tese de doutorado - Universidade Federal da Bahia. Salvador: UFBA, 2007.

FIORE, Maurício. O lugar do Estado na questão das drogas: o paradigma proibicionista e as alternativas. Novos estud. - CEBRAP[online]. 2012, n.92 [cited 2018-07-11], pp.921.

FOUCAULT, M. História da sexualidade: a vontade de saber. Trad. Maria Thereza Albuquerque e J. A. Albuquerque, 15ª ed. Rio de Janeiro: Graal, 2003.

GOMES, B. R., \& ADORNO, R. d. Tornar-se "noia": trajetória e sofrimento social nos "usos de crack" no centro de São Paulo. Etnográfica [Online], 2011. pp. 569-586.

GRUND, J.-P. C. Drug use as a social Ritual: Functionality, symbolism and determinants of self-regulation. Rotterdam : Institute Voor Verslavingsondersoek, Erasmus Universiteit, 1993.

HERZFELD, Michael. Cultural Intimacy: Social Poetics in the Nation State. New York: Routledge, 1997.

INGOLD, T. Estar vivo: ensaios sobre movimento, conhecimento e descrição. Editora Vozes, 2015 [2011].

JOHNSON, J. Trust and Personal Involvements in Fieldwork. In: R. Emerson, Contemporary Field Research: A Collection of Readings. Boston/Toronto: Little Brown and Company, 1983. pp. 203-215.

LABATE, B. C.; GOULART, S.; FIORE, M.; MACRAE, E.; CARNEIRO, H. (orgs.), Drogas e cultura: novas perspectivas. Salvador: EDUFBA, 2008. pp. 383-408. 
LATOUR, B. Jamais Fomos Modernos. São Paulo: Ed. 34, 1994.

MACRAE, E. Abordagens qualitativas na compreensão do uso de psicoativos. In: TAVARES, L. A.; ALMEIDA, A. B.; MACRAE, E.; FERREIRA, O. S. Drogas: tempos, lugares e olhares sobre seu consumo. Salvador: EDUFBA;CEETAD/UFBA, 2004. pp. $27-48$.

Introdução. In: MACRAE, E. ; TAVARES, L. R.; NUÑES, M. E. Crack: contextos, padrões e propósitos de uso. Salvador: EDUFBA, 2013.

MACRAE, E. \& VIDAL, S. S. A Resolução 196/96 e a imposição do modelo biomédico na pesquisa social: dilemas éticos e metodológicos do antropólogo pesquisando o uso de substâncias psicoativas. Revista de Antropologia, 49(2), 2006. pp. 645-666.

MALHEIRO, L. Tornando-se um usuário de crack. In: NERY FILHO, A.; MACRAE, E.; TAVARES, L.; RÊGO, M. ; NUÑEZ, M. E. As drogas na contemporaneidade: perspectivas clínicas e culturais Salbador: UFBA, 2012. pp. 79-100.

"Entre sacizeiro, usuário e patrão": Um estudo etnográfico sobre consumidores de crack no Centro Histórico de Salvador. In: MACRAE, E. Crack: contextos, padrões e propósitos de uso. Salvador: EDUFBA, 2013. pp. 154-227.

MALINOWSKI, B. Argonautas do pacífico ocidental: um relato do empreendimento e da aventura dos nativos nos arquipélagos da Nova Guiné Melanésia. São Paulo: Abril Cultural, 1978 [1922].

MERCANTE, M. Imagens de cura: Ayahuasca, imaginação, saúde e doença na Barquinha. Rio de Janeiro: Editora FIOCRUZ, 2012.

OLIVEIRA, R. C. O trabalho do antropólogo: olhar, ouvir, escrever. In: O trabalho do antropólogo. São Paulo/Brasília: Unesp/Paralelo 15, 1998.

. "Pesquisa em versus pesquisa com seres humanos", in VICTORIA et al. (orgs.), Antropologia e ética: o debate atual no Brasil, Niterói, Editora da Universidade Federal Fluminense, 2004. pp. 33-44.

RUI, T. Corpos Abjetos: etnografia em cenários de uso e comércio de crack. Tese de doutoramento. Campinas: UNICAMP/IFCH, 2012.

SILVA, S. L. Mulheres da Luz: uma etnografia dos usos e preservação no uso do "Crack". Dissertação (Mestrado em Serviços de Saúde Pública). São Paulo: Faculdade de Saúde Pública, Universidade de São Paulo, 2000.

STRATHERN, M. Property, substance, and effect. anthropological essays on persons and things, London: Athlone Press, 1999. pp. 117-135.

TURNBULL, C. Sex and gender: The role of subjectivity in field research. In: C. Turnbull, Self, sex and gender in cross-cultural fieldwork. Urbana: University of Illinois Press, 1986. pp. 17-29. 
VAN MAANEN, J. The Moral Fix: On the Ethics of Fieldwork. In: R. Emerson., Contemporary Field Research: A Collection of Readings. Boston/Toronto: Little Brown and Company, 1983. pp. 269-287.

VIVEIROS DE CASTRO, Eduardo. "O Nativo Relativo”. Mana, 8(1), 2002. pp. 113 -148.

WAGNER, Roy. The Invention of Culture. Chicago: The University of Chicago Press, 1981 [1975].

WHYTE, W. F. Sociedade de esquina. Rio de janeiro: Jorge Zahar, 2005[1943].

ZINBERG, N. E. Drug, Set, and Setting: The Basis for Controlled Intoxicant Use. Yale University Press, 1984.

autores Ygor Diego Delgado Alves

Pesquisador de pós-doutorado na Universidade Federal de São Paulo. Possi graduação e mestrado em Ciências Sociais, ambos pela PUC-São Paulo, e doutorado em Antropologia pela Universidade Federal da Bahia.

Pedro Paulo Gomes Pereira

Professor livre-docente da Universidade Federal de São Paulo, possui mestrado e doutorado em Antropologia pela Universidade de Brasília e pós-doutorado pela Universidade de Barcelona.

Recebido em: 06/10/2017 Aceito em: 07/12/2018 